OPEN ACCESS

Edited by:

Nejat Duzgunes,

University of the Pacific, United States

Reviewed by:

Elias Fattal,

Université Paris-Sud, France

Lingxiang Mao,

Affiliated Hospital of Jiangsu

University, China

${ }^{*}$ Correspondence:

Qiwei Qin

qinqw@scau.edu.cn

Pengfei $L$

pfli2014@126.com

Specialty section:

This article was submitted to

Virology,

a section of the journal

Frontiers in Microbiology

Received: 10 November 2019

Accepted: 23 March 2020

Published: 30 April 2020

Citation:

Zhou L, Wang S, Yu Q, Wei S, Liu M, Wei J, Huang Y, Huang X, Li P and Qin $Q$ (2020) Characterization

of Novel Aptamers Specifically Directed to Red-Spotted Grouper

Nervous Necrosis Virus

(RGNNV)-Infected Cells for Mediating

Targeted siRNA Delivery.

Front. Microbiol. 11:660.

doi: 10.3389/fmicb.2020.00660

\section{Characterization of Novel Aptamers Specifically Directed to Red-Spotted Grouper Nervous Necrosis Virus (RGNNV)-Infected Cells for Mediating Targeted siRNA Delivery}

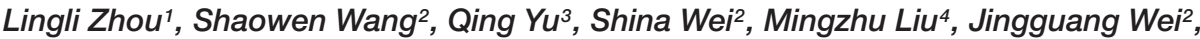 \\ Youhua Huang ${ }^{2}$, Xiaohong Huang ${ }^{2}$, Pengfei Li ${ }^{3 *}$ and Qiwei Qin ${ }^{2 \star}$
}

${ }^{1}$ School of Life Sciences, Sun Yat-sen University, Guangzhou, China, ${ }^{2}$ Guangdong Laboratory for Lingnan Modern Agriculture, College of Marine Sciences, South China Agricultural University, Guangzhou, China, ${ }^{3}$ Guangxi Key Laboratory of Marine Natural Products and Combinatorial Biosynthesis Chemistry, Guangxi Beibu Gulf Marine Research Center, Guangxi Academy of Sciences, Nanning, China, ${ }^{4}$ Guangxi Key Laboratory of Marine Environmental Science, Guangxi Academy of Sciences, Nanning, China

Nervous necrosis virus (NNV) causes viral nervous necrosis, the most devastating disease in more than 50 fish species worldwide, with massive mortality rates up to $100 \%$, resulting in great economic losses to mariculture. However, few methods are available for the efficient diagnosis and treatment of viral nervous necrosis. Aptamers are molecular recognition ligands characterized by their remarkably high specificity and affinity, great stability, and ease of synthesis, and have been widely studied in application of disease diagnosis and therapies. In this study, we generated three aptamers against red-spotted grouper nervous necrosis virus (RGNNV)-infected grouper brain (GB) cells using the Cell-SELEX (cell based-systematic evolution of ligands by exponential enrichment) technology. The selected aptamers formed stable stem-loop structures, and could specifically recognize RGNNV-infected GB cells, with calculated dissociation constants $\left(K_{d}\right)$ of 27.96, 29.3, and 59.5 nM for aptamers GBN2, GBN10, and GBN34, respectively. They also recognized RGNNV-infected brain tissues. The three aptamers were non-toxic and showed antiviral activities both in vitro and in vivo. Fluorescence microscopy and flow cytometry also demonstrated that aptamer GBN34 could be efficiently and specifically internalized into RGNNV-infected GB cells. The targeted cellular delivery of aptamer-small interfering RNA (siRNA) conjugates remarkably inhibited RGNNV infection in GB cells. The efficiency of the aptamer-based targeted delivery system was about $75 \%$ reduction in infection after $48 \mathrm{~h}$, which was similar to that of transfection. These aptamers have great potential utility in the rapid diagnosis and inhibition of RGNNV infection in mariculture.

Keywords: aptamer, Cell-SELEX, red-spotted grouper nervous necrosis virus, antiviral activity, targeted delivery, siRNA 


\section{INTRODUCTION}

Nervous necrosis virus (NNV), one of the most devastating marine viruses, typically causes viral nervous necrosis (VNN) or viral encephalopathy and retinopathy (VER) in the larvae and juveniles of marine and freshwater fish (Souto et al., 2019). In recent years, NNV has spread to more than 50 fish species around Europe, Australia, Martinique, North America, Tahiti, and Asia (Liu et al., 2012; Doan et al., 2017). In severe outbreaks, NNV resulted in high mortality up to $100 \%$ within a week (Munday et al., 2002). NNV could be divided into four clade: barfin flounder nervous necrosis virus (BFNNV), striped jack nervous necrosis virus (SJNNV), tiger puffer nervous necrosis virus (TPNNV), and red-spotted grouper nervous necrosis virus (RGNNV) (Nishizawa et al., 1997). Among these, RGNNV is the commonest pathogen associated with fish VNN diseases in Southeast Asian countries and China (Xu et al., 2010). Vacuolization of the brain and retinal tissues can be seen in infected fish, and common symptoms of VNN include abnormal whirling and spiraling, dark body color, and loss of appetite. However, our knowledge of NNV infection and treatment is still limited, and there is no efficient commercial therapeutic regimen for VNN.

Aptamers are functional single-stranded DNA (ssDNA) or ssRNA molecules isolated from random oligonucleotides pools using the selective evolution of ligands by exponential enrichment (SELEX) (Stoltenburg et al., 2007). They could bind to a variety of targets with high specificity and affinity, similar to antibodies (Li et al., 2015a; Fattal et al., 2018; Yu et al., 2019a). However, aptamers have many advantages over antibodies, including their selection in vitro, easy synthesis and modification, high reproducibility, long-term stability, small size, and low immunogenicity (Kovacevic et al., 2018). In recent decades, aptamers have begun to compete with antibodies in the rapid detection of specific molecules and therapeutic applications (Shangguan et al., 2006; Tan et al., 2013). For instance, the product Macugen, based on the PEGylated form of the antihuman vascular endothelial growth factor (VEGF) aptamer, was approved in 2004 (United States) and 2006 (Europe) (Chapman and Beckey, 2006). Phase 1 studies for the product development of an RNA aptamer targeting factor IXa were completed in 2006 (Dyke et al., 2006). Many aptamers directed against purified virions, viral proteins, and viral infected cells show great potential utility in viral research, detection, and inhibition (Li et al., 2014, 2015b). For example, a chip-based detection method for hepatitis $\mathrm{C}$ virus (HCV) was developed with aptamers directed against the HCV core antigen (Lee et al., 2007). In a previous study, we characterized three aptamers with antiviral activities directed against the RGNNV coat protein (CP) protein (Zhou et al., 2016).

When cells are infected by a virus, their surfaces are modified by the insertion of viral proteins. These modifications and alterations could be important biomarkers of virus-infected cells, and served as therapeutic targets against viral infection (Kim et al., 2018; Zhu and Chen, 2018). However, known biomarkers of specific viral infections are still limited. Nucleic acid probes (aptamers) generated by Cell-SELEX could specifically bind to modified proteins or biomarkers that occurred during viral infection (Zhu and Chen, 2018). Furthermore, the identified aptamers' targets serve as potential biomarkers of viral infection (Fang and Tan, 2010; Ye et al., 2012). For example, Parekh et al. (2010) selected aptamers for vaccinia virus (VV)-infected cells using Cell-SELEX, and identified A56R, the target of the aptamer, as a potential biomarker of VV infection. Aptamers could also be used in drug delivery. Zhou and Rossi (2012) reported the use of aptamer-siRNA conjugates as a cell-type-specific delivery system for the inhibition of human immunodeficiency virus 1 (HIV-1).

In this study, we applied Cell-SELEX to generate three ssDNA aptamers (GBN2, GBN10, and GBN34) specifically directed against RGNNV-infected grouper brain (GB) cells (RGNNVGB cells). The binding specificity and affinity of the aptamers for RGNNV-GB cells were determined, and we evaluated the cytotoxicity, histological toxicity, and antiviral activities of the three aptamers, both in vitro and in vivo. The cell-specific internalization of aptamers was demonstrated, and an aptamersiRNA delivery system was established to evaluate the antiviral ability against RGNNV infection. This is the first time that aptamers directed against RGNNV-infected GB cells have been generated and applied to siRNA delivery for inhibition of RGNNV infection.

\section{MATERIALS AND METHODS}

\section{Ethics Statement}

All experimental procedures on animals were approved by the Ethical Committee of College of Marine Sciences, South China Agricultural University. Our animal experiments were conducted in accordance with the guidelines issued by the Ethics Committee of South China Agricultural University. All sections of this report adhere to the ARRIVE (Animal Research: Reporting in vivo Experiments guidelines for reporting animal research).

\section{Fish, Cells, Virus, and Reagents}

Healthy fry $(3-4 \mathrm{~cm})$ and juveniles $(8-10 \mathrm{~cm})$ of the grouper Epinephelus coioides were purchased from a fish farm in Hainan Province, China. Before the experiment, the fish were temporarily cultured in an air-pumped laboratory recirculating seawater system ( $2.5 \%$ salinity) for 2 weeks.

Grouper brain cells, which are permissive to RGNNV, were propagated in Leibovitz's L15 medium (Gibco, Grand Island, NY, United States) supplemented with $10 \%$ fetal bovine serum (FBS; Life Technologies, Carlsbad, CA, United States) at $25^{\circ} \mathrm{C}$, as described previously (Huang et al., 2011). RGNNV is maintained in our laboratory. The $50 \%$ tissue culture infectious dose $\left(\mathrm{TCID}_{50}\right)$ of the RGNNV stock in the GB cells was determined as described previously (Reed and Muench, 1938).

\section{Initial Random ssDNA Library and Primers for Cell-SELEX}

The synthetic initial ssDNA library (Sigma-Aldrich, St. Louis, MO, United States) consisted of a central randomized sequence of 50 nucleotides (nt) flanked by two primer hybridization sites (5'-GACGCTTACTCAGGTGTGACTCG$\mathrm{N}_{50}$-CGAAGGACGCAGATGAAGTCTC-3'). A fluorescein 
isothiocyanate (FITC)-labeled forward primer (5'-FITCGACGCTTACTCAGGTGTGACTCG- $3^{\prime}$ ) and a biotinylated reverse primer (5'-biotin-GAGACTTCATCTGCGTCCTTCG$\left.3^{\prime}\right)$ were used for the PCRs.

\section{Cell-SELEX}

The SELEX procedure was performed essentially as described previously, with modifications (Li et al., 2015b). GB cells were grown to $100 \%$ confluence in $60 \mathrm{~mm}$ cell culture dishes (Corning Inc., Corning, NY, United States), infected with RGNNV at a multiplicity of infection (MOI) of 1 , and incubated at $25^{\circ} \mathrm{C}$ for $24 \mathrm{~h}$. The initial ssDNA library $(10 \mathrm{nmol})$ was denatured by heating at $95^{\circ} \mathrm{C}$ for $5 \mathrm{~min}$, cooled on ice for $10 \mathrm{~min}$, and then dissolved in $1000 \mu \mathrm{l}$ of binding buffer $(5 \mathrm{~g} / \mathrm{L}$ glucose, 10\% FBS; Life Technologies) containing $1.0 \mathrm{~g} / \mathrm{L}$ bovine serum albumin (Solarbio, Beijing, China), $0.1 \mathrm{mg} / \mathrm{ml}$ yeast tRNA (Invitrogen, Carlsbad, CA, United States), and $5 \mathrm{mM} \mathrm{MgCl}_{2}$. The ssDNA mixture was then incubated with RGNNV-infected cells for $60 \mathrm{~min}$ at $4^{\circ} \mathrm{C}$. After being washed with washing buffer (10 $\mathrm{mM}$ Tris- $\mathrm{HCl}, 5 \mathrm{~g} / \mathrm{L}$ glucose, $9 \mathrm{~g} / \mathrm{L} \mathrm{NaCl}$, and $5 \mathrm{mM}$ $\mathrm{MgCl}_{2}$ ), the bound ssDNAs were eluted from the collected cells by incubation at $95^{\circ} \mathrm{C}$ for $5 \mathrm{~min}$. After centrifugation, the supernatant containing the ssDNAs was collected for PCR. The amplified products were denatured by heating at $95^{\circ} \mathrm{C}$ for $5 \mathrm{~min}$ and then renatured by cooling immediately on ice for $5 \mathrm{~min}$. The sense ssDNAs were separated from the biotinconjugated antisense strands using streptavidin-coated Sepharose beads (Promega, United States) as previously described (Paul et al., 2009). The collected sense ssDNAs were used in the next round of selection. To evolve aptamer candidates with high affinity and specificity, the incubation time was reduced, the washing strength was increased, the number of RGNNVGB cells was gradually reduced, and counter selection was incorporated into the third and subsequent selection cycles. For counter selection, we incubated normal GB cells with the sense ssDNAs and collected the supernatant for the next round of selection. The 10th enriched ssDNA library was amplified, cloned, and sequenced. The candidate aptamer sequences were aligned and clustered with ClustalW2 (Chenna et al., 2003). The final aptamers were predicted with the MFold program ${ }^{1}$ (Yang et al., 2013).

\section{Specificity Analysis of Aptamer Candidates Recognizing RGNNV Infected GB Cells by Flow Cytometry}

Flow cytometry was used to monitor the enrichment of the selection library and to measure the specific binding of each candidate aptamer to RGNNV-GB cells. Predenatured FITClabeled aptamer candidates $(200 \mathrm{nM})$ were cooled on ice for $5 \mathrm{~min}$ and then incubated with $5 \times 10^{5}$ RGNNV-GB cells in binding buffer for $1 \mathrm{~h}$. After incubation, the cells were washed three times with phosphate-buffered saline (PBS) and suspended in $400 \mu \mathrm{l}$ of PBS. Fluorescence was measured with a FACS Calibur flow cytometer (BD Biosciences, United States) by counting 20,000

${ }^{1}$ http://mfold.rna.albany.edu/?q=mfold/DNA-Folding-Form events. FITC-labeled aptamer candidates incubated with normal GB cells were used as the negative controls.

\section{Specific Binding of Aptamers to RGNNV-GB Cells Detected With Fluorescence Microscopy}

For fluorescent imaging, the carboxytetramethylrhodamine (TAMARA)-labeled aptamers $(200 \mathrm{nM})$ were denatured at $95^{\circ} \mathrm{C}$ for $5 \mathrm{~min}$, and cooled on ice for $5 \mathrm{~min}$. They were then added to RGNNV-GB cells in $35 \mathrm{~mm}$ glass bottom dishes (Cellvis, catalog number D35-14-1-N). After incubation at $4^{\circ} \mathrm{C}$ for $1 \mathrm{~h}$ in a darkroom, unbound aptamers were washed off, and $4 \%$ paraformaldehyde was added to the cells to fix them. The aptamers incubated with uninfected GB cells and SGIV-infected GB cells were used as controls. The cells were imaged on a Leica DMRXA fluorescence microscope (Leica, Wetzlar, Germany).

\section{Specific Binding of Aptamers to RGNNV-Infected Brain Tissue Detected With Fluorescence Microscopy}

Each individual grouper, E. coioides, was starved for $24 \mathrm{~h}$ and then intraperitoneally injected with $40 \mu \mathrm{l}$ of $10^{7} \mathrm{TCID}_{50} / \mathrm{ml}$ RGNNV. Grouper fry injected with PBS served as the controls. Each group contained 30 grouper fry. After 1 week, the brain tissues of each group were collected and fixed in 10\% neutral-buffered formalin. The fixed tissue sections were stored before the subsequent experiment. The frozen tissue sections were incubated with TAMARA labeled aptamers $(200 \mathrm{nM})$ at $4^{\circ} \mathrm{C}$ for $1 \mathrm{~h}$ in a darkroom. After the samples were washed with PBS, the tissues were imaged with a Leica DMRXA fluorescence microscope. Tissue sections incubated with the TAMARA-labeled initial library were used as the controls.

\section{Measurement of Aptamer Affinity}

The procedure used to measure the binding affinity of the aptamers has been reported previously by $\mathrm{Li}$ et al. (2015a). The mean fluorescence intensity of the FITC-labeled aptamers bound to RGNNV-GB cells was used to calculate their equilibrium dissociation constants $\left(K_{d}\right)$ according to the equation $Y=B_{\max } X /\left(K_{d}+X\right)$ with SigmaPlot. $B_{\max }$ indicated the maximum mean fluorescence intensities of target cells bound with aptamers. $Y$ indicated the mean fluorescence intensities of target cells bound with aptamers at corresponding concentrations $(X)$. Results from three independent experiments are presented as the mean $\pm \mathrm{SD}$.

\section{Trypsin Treatment of RGNNV-Infected GB Cells}

Red-spotted grouper nervous necrosis virus-infected grouper brain cells $\left(5 \times 10^{5}\right)$ were digested with $1 \mathrm{ml}$ of 0.25 ? $\%$ trypsin (Thermo Scientific HyClone) at $28^{\circ} \mathrm{C}$ for $10 \mathrm{~min}$. Then, medium supplemented with $10 \%$ FBS was added to inhibit the activity of trypsin. After washing with PBS three times, trypsin-treated cells were incubated with FITC-labeled aptamers. Fluorescence was assessed with a FACScan cytometer by counting 20,000 events as described previously (Li et al., 2015a). 


\section{Cytotoxicity and Histological Toxicity Analyses}

For the cytotoxicity analysis, GB cells were seeded in 96well plates for $18 \mathrm{~h}$. Each aptamer was serially diluted to produce a concentration gradient $(0,1,10,100$, and $1000 \mathrm{nM}$ ), and added into GB cells in 96-well plates for $48 \mathrm{~h}$. The cytotoxicity of the aptamers was measured by cell proliferation reagent WST-1 (Roche, Mannheim, Germany)based colorimetric assay, according to the manufacturer's instructions. Three independent experiments were performed for each set of experimental conditions.

For the histological toxicity analysis, healthy grouper (E. coioides) were starved for $24 \mathrm{~h}$ before the experiment. Each grouper was then injected intraperitoneally with each aptamer (GBN2, GBN10, and GBN34; $1000 \mathrm{nM}$ ). There were two control groups: control 1, normal grouper received no injection; control 2, grouper injected with PBS. Each treatment group contained 10 fry. Mortality was recorded daily until no further mortality occurred. The histological toxicity of aptamer GBN34 using hematoxylin-eosin ( $\mathrm{H} \& \mathrm{E})$ staining was analyzed as described previously (Zhou et al., 2016).

The toxicity of aptamers was also assessed by biochemical parameters, including alanine aminotransferase (ALT), aspartate aminotransferase (AST), and creatinine (Cr). The liver of the experimental fish was weighed maximum up to $0.1 \mathrm{~g}$ and homogenized in $2 \mathrm{ml}$ of $0.5 \mathrm{M}$ (pH 7.4) Tris- $\mathrm{HCl}$ buffer. The mixture was then centrifuged at $8000 \mathrm{rpm}$ for $15 \mathrm{~min}$ at $4^{\circ} \mathrm{C}$ and the supernatant was collected for the analysis of ALT and AST. The activities of AST and ALT were measured using a transaminase assay kit (Transaminase C II-test, Wako, Osaka, Japan), according to the manufacturer's instructions. Blood was gathered from the caudal veins and kept in clean tubes, left for $2 \mathrm{~h}$, and then centrifuged at $3000 \mathrm{rpm}, 4^{\circ} \mathrm{C}$, for $15 \mathrm{~min}$, followed by serum separation. The serum $\mathrm{Cr}$ was measured using Creatinine Assay Kit (Abcam, Cambridge, United Kingdom), according to the manufacturer's instructions.

\section{Inhibition of RGNNV Infection in vitro}

The inhibition of RGNNV infection by selected aptamers in vitro was analyzed as previously described (Liang et al., 2013), with a few modifications. GB cells were seeded in 24-well plates for $18 \mathrm{~h}$. Each aptamer $(200 \mathrm{nM})$ and RGNNV $(\mathrm{MOI}=0.5)$ were then added to the GB cells at $28^{\circ} \mathrm{C}$ for $24 \mathrm{~h}$. To assess the dose effects of the aptamers on RGNNV infection, different concentrations $(100,250,500$, and $1000 \mathrm{nM})$ of aptamer (GBN2) were added to the GB cells. There were two control groups: 1: GB cells incubated with RGNNV (MOI $=0.5)$ alone, 2: GB cells incubated with the mixtures of initial random library $(1000 \mathrm{nM})$ and RGNNV (MOI $=0.5)$. After infection with RGNNV at $28^{\circ} \mathrm{C}$ for 12 and $24 \mathrm{~h}$, respectively, we imaged the cell morphology and cytopathic effects (CPEs; vacuolation) with light microscopy. We also collected cells from each well to measure the relative expression of $\mathrm{CP}$ mRNA with quantitative real-time reverse transcription (RT)-PCR (qRT-PCR), using previously described methods (Huang et al., 2015). The results of three independent experiments were averaged. Another batch of cells were collected and lysed with low-salt lysis buffer for Western blot (WB). Proteins were transferred to polyvinylidene fluoride (PVDF) membranes (Bio-Rad, CA, United States) and further incubated with the anti-CP antibodies. The LumiGlo Chemiluminescent Substrate System (KPL, Guildford, United Kingdom) was used for protein detection.

To determine the antiviral activities of aptamers to RGNNVinfected cells, each aptamer was added to the infected cells (12 hp.i.). After aptamer treatment for 12 and $24 \mathrm{~h}$, respectively, we collected cells to measure the relative expression of CP mRNA with qRT-PCR and CP protein level with WB, as described above.

\section{Inhibition of RGNNV Infection in vivo}

Healthy E. coioides fry $(3-4 \mathrm{~cm})$ were starved for $24 \mathrm{~h}$ before the experiment. Each grouper was then injected intraperitoneally with a mixture of $40 \mu \mathrm{l}$ of $10^{7} \mathrm{TCID}_{50} / \mathrm{ml}$ RGNNV and each aptamer (GBN2 and GBN34; $1000 \mathrm{nM}$ ). There were five control groups: control 1, grouper fry injected with a mixture of the same amounts of RGNNV and the initial random library; control 2, grouper fry injected with RGNNV alone; control 3, grouper fry injected with aptamer GBN2 alone; control 4, grouper fry injected with aptamer GBN34 alone; control 5, grouper fry injected with PBS. Each treatment group contained 30 fry. Mortality was recorded daily until no further mortality occurred.

\section{Cell-Specific Internalization Study of GBN34}

A fluorescence-microscopy-based analysis of cell-specific internalization was performed as previously described, with some modification (Xiao et al., 2008). GB cells were seeded in $35 \mathrm{~mm}$ glass bottom dishes (Cellvis) for $18 \mathrm{~h}$ before infection. RGNNV (MOI $=1$ ) was then added to the GB cells, which were then cultured at $28^{\circ} \mathrm{C}$ for $8 \mathrm{~h}$. After being washed twice with PBS, RGNNV-GB cells were incubated with FITC-labeled aptamer GBN34 $(200 \mathrm{nM})$ in $\mathrm{L} 15$ medium at $28^{\circ} \mathrm{C}$ for $2 \mathrm{~h}$. A quick wash with $\mathrm{NaOH}(200 \mathrm{mM})$ was used to remove any cell-surface-bound aptamer before the internalization study. The cells were then washed twice with PBS and visualized under a Leica DMRXA fluorescence microscope. RGNNV-GB cells incubated with the FITC-labeled ssDNA library $(200 \mathrm{nM})$ and uninfected GB cells incubated with the FITC-labeled aptamer GBN34 (200 nM) were used as the control.

For the flow-cytometric analysis of cell-specific internalization, GB cells were seeded and incubated in sixwell plates for $18 \mathrm{~h}$. RGNNV (MOI $=1)$ was then added to infect the GB cells, and incubated at $28^{\circ} \mathrm{C}$ for $8 \mathrm{~h}$. After the RGNNV-GB cells were washed twice with PBS, they were incubated with FITC-labeled aptamer GBN34 (200 nM) in $\mathrm{L} 15$ for $2 \mathrm{~h}$ at $28^{\circ} \mathrm{C}$. FITC-labeled aptamer GBN34 (200 nM) incubated with RGNNV-infected cells at $4^{\circ} \mathrm{C}$ served as the control group. The cells were then washed twice with PBS. Fluorescence in the target cells was assessed with a FACScan cytometer by counting 20,000 events. The results of three independent experiments were averaged. 


\section{Assembly of Aptamer-siRNA Conjugate}

The aptamer-siRNA conjugate was assembled as previously described, with some modification (Chu et al., 2006). The biotinlabeled siRNA (Bio-siRNA) and control Bio-siRNA (Bio-NC) were designed and synthesized by RiboBio (Guangzhou, China). The following RNA oligonucleotides were used in this study:

control siRNA (siRNA-NC) forward: 5'-CAAGUAAA GACUGCCUAAU-3'

Reverse: $5^{\prime}$-AUUAGGCAGUCUUUACUUG-3'

RGNNV CP siRNA \#1 forward: 5'-UCGUCGGCGUA GUAAUCGCTT-3'

Reverse: 5'-GCGAUUACUACGCCGACGATT-3'

RGNNV CP siRNA \#2 forward: 5'-CCUCGACUGUAA CUGGAUUTT-3'

Reverse: 5'-AAUCCAGUUACAGUCGAGGTT-3'

The biotin-labeled aptamer $(\mathrm{GBN} 34)$ was denatured at $95^{\circ} \mathrm{C}$ for $5 \mathrm{~min}$ and cooled on ice for $5 \mathrm{~min}$. The aptamer-siRNA conjugates were assembled by mixing the biotin-labeled siRNA and aptamer, and streptavidin at the molar ratio of 2:2:1 for $15 \mathrm{~min}$. The conjugation of the aptamer and siRNA to streptavidin was confirmed with a gel-shift analysis.

We examined the silencing effects of siRNAs by measuring the relative viral CP mRNA expression by qRT-PCR, using previously described methods (Huang et al., 2015). GB cells were seeded in 24-well plates for $18 \mathrm{~h}$. The cells were then transfected with siRNAs or Bio-siRNAs at a concentration of 100 or $200 \mathrm{nM}$ using Lipofectamine 2000, according to the manufacturer's instructions. After transfection for $24 \mathrm{~h}, \mathrm{RGNNV}$ (MOI = 0.5) was added to the GB cells for culture. GB cells transfected with Bio-NC (200 nM) were used as the control. We collected the cells from each well to measure the relative CP mRNA expression with qRT-PCR, using previously described methods (Huang et al., 2015). The results of three independent experiments were averaged.

\section{Cellular Delivery of Aptamer-siRNA Conjugates for Inhibition of RGNNV Infection}

The aptamer-siRNA conjugate, at a final concentration of 50 $\mathrm{nM}$ (100 nM aptamer; on average, two aptamers/conjugate), and RGNNV (MOI $=0.5$ ) were added to GB cells for culture. GB cells to which aptamer $(200 \mathrm{nM})$ and RGNNV $(\mathrm{MOI}=0.5)$ were added were used as a control. Another control consisted of GB cells to which only RGNNV (MOI $=0.5)$ was added. To evaluate the efficiency of delivery, we used a matched group in which GB cells were transfected with $50 \mathrm{nM}$ conjugate for $24 \mathrm{~h}$ before RGNNV (MOI = 0.5) was added to the cells. GB cells in other wells were transfected with Bio-NC to test the effects of the transfection reagents. We collected the cells from each well to measure the relative CP mRNA expression with qRT-PCR, using previously described methods (Huang et al., 2015). The results of three independent experiments were averaged.

To determine the antiviral activities of aptamer-siRNA conjugates to RGNNV-infected cells, the conjugate was added to the RGNNV-infected cells (12 hp.i.). After aptamer treatment for
24 and $36 \mathrm{~h}$, we collected cells to measure the relative expression of CP mRNA with qRT-PCR.

\section{RESULTS}

\section{Cell-SELEX Targeting RGNNV-GB Cells and the Enrichment of Aptamer Candidates}

We used flow cytometry to monitor the enrichment of the ssDNA pools. As shown in Figure 1A, the fluorescence intensity of the ssDNA pools bound to RGNNV-GB cells increased as the SELEX progressed, whereas there was no obvious increase in the fluorescence intensity of the ssDNA pools incubated with uninfected GB cells. The shift in the fluorescent signal showed that the 10th ssDNA pool bound most strongly to the RGNNVGB cells. Therefore, we cloned and sequenced the highly enriched 10th ssDNA pool.

Three candidate aptamers, GBN2, GBN10, and GBN34 (Table 1), were isolated from the sequenced pools for further analysis, based on the results of a multiple sequence alignment. Prediction of the secondary structures of the selected aptamers revealed that the three aptamers all formed stable stem-loop structures, and GBN2, GBN10, and GBN34 displayed $\Delta G$ values of $-6.28,-19.25$, and $-18.84 \mathrm{~kJ} / \mathrm{mol}$, respectively (Figure 1B).

\section{Characterization of Aptamers for RGNNV-GB Cells and RGNNV-Infected} Brain Tissues

The binding properties of each aptamer (GBN2, GBN10, or GBN34) to RGNNV-GB cells were analyzed further. In each case, the increased fluorescence intensity detected with flow cytometry indicated that the aptamer bound to RGNNV-GB cells. Fluorescence microscopy also showed that each aptamer bound to RGNNV-infected GB cells and brain tissue, but not to uninfected GB cells, SGIV-infected GB cells, or uninfected grouper brain tissue, which was consistent with the results of flow cytometry (Figures 2A-C). The calculated dissociation constants $\left(K_{d}\right)$ for GBN2, GBN10, and GBN34 for RGNNV-GB cells were 27.96, 29.3, and 59.5 nM, respectively (Figure 2D). To determine the target molecules recognized by these aptamers, trypsin treatment was used to remove the membrane protein of cells. As indicated by the fluorescence intensity, the binding of the three aptamers to RGNNV-infected cells was almost completely abolished by trypsin treatment (Figure 2E).

\section{Cytotoxicity and Histological Toxicity of the Aptamers}

The cell viability analysis with a WST-1-based colorimetric assay showed that the three aptamers had no significant cytotoxic effect on GB cells, even at rather high concentration of $1000 \mathrm{nM}$ (Figure 3A). The toxicity test performed in vivo showed that the cumulative mortality rate remained at $0 \%$ and the fish were still healthy after 10 days of each aptamer injection. A histological toxicity analysis of GBN34 also proved no obvious pathological changes in the liver or spleen tissues of the fish tested (Figure 3B). 


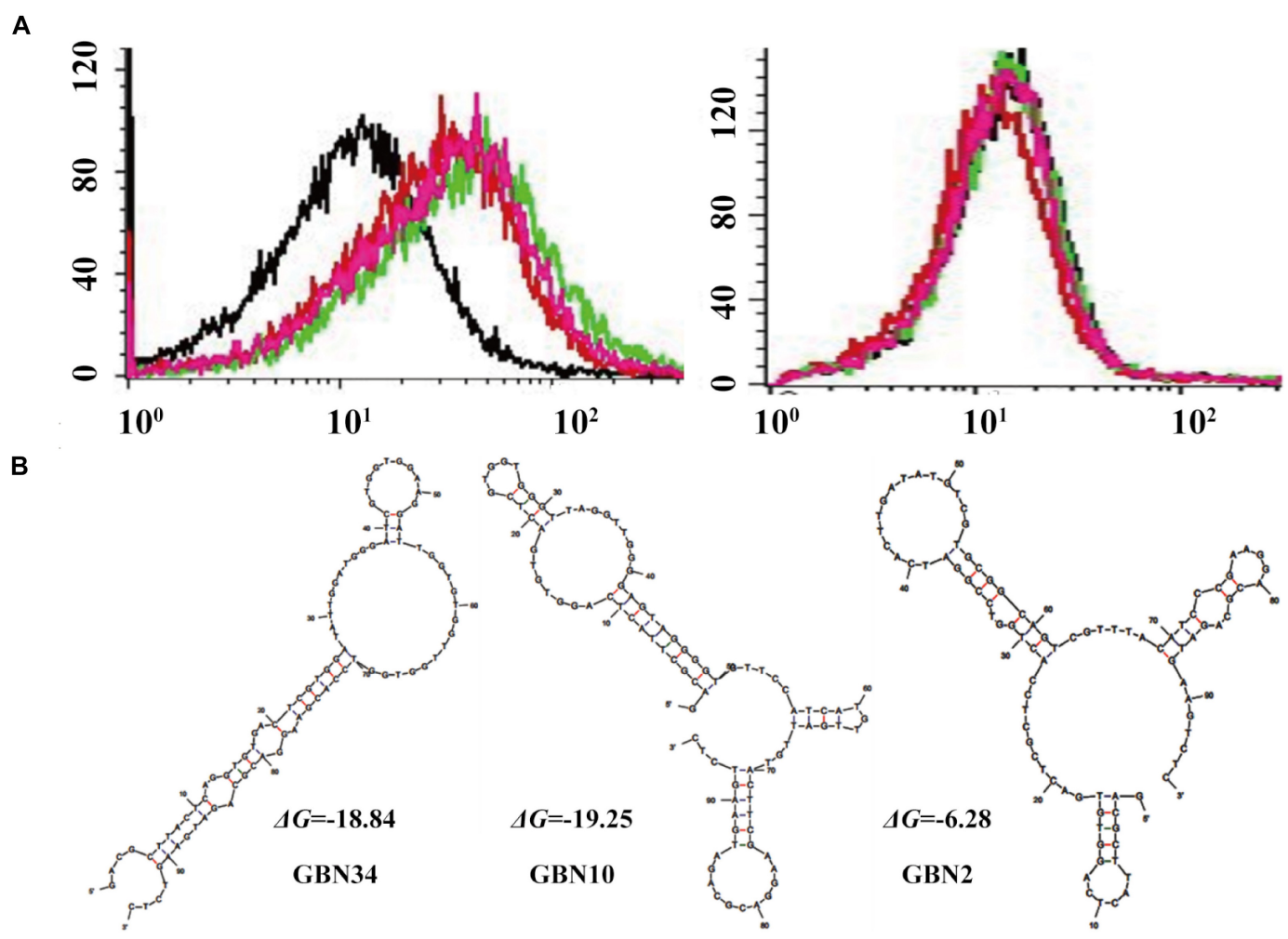

FIGURE 1 | Selection of three aptamers that specifically recognized RGNNV-GB cells by cell-systematic evolution of ligands by exponential enrichment (Cell-SELEX) technology. (A) Binding of FITC-labeled DNA pools to RGNNV-infected GB cells was enhanced after more rounds of selection (left). Black, initial library; red, 9th round of selection; green, 10th round of selection; pink, 11th round of selection. FITC-labeled DNA pools bound to uninfected GB cells served as a control (right). (B) Predicted secondary structures of aptamers (GBN2, GBN10, and GBN34). The stabilities of the aptamer secondary structures were calculated as the free energy values $(\Delta G)$.

TABLE 1 | Identification of ssDNA aptamers.

\begin{tabular}{|c|c|c|}
\hline Aptamer & Central randomized sequences & Frequency \\
\hline GBN34 & TGGATATTGGATGGGATCGTGGTGGAAGGATTGGTGTGGTTGGTGGTCCA & $46 \%$ \\
\hline GBN2 & CTCCACTGGTCCGGATCACTTGATATGTCGTGCGGCAGTCGTTACATCC & $30 \%$ \\
\hline GBN10 & TGGTGGGTTAGGTTGGGGAGTAGGGGTGTTCCATCATGTTGATTGTACTT & $24 \%$ \\
\hline
\end{tabular}

Frequency indicates the percentage of the 11th selected pool comprised by each aptamer.

Hepatic enzymes (ALP and AST) and serum Cr of aptamersinjected groups displayed no significant difference to that of controls (Figure 3C). Thus, all three aptamers were non-toxic both in vitro and in vivo.

\section{Antiviral Effects of Aptamers Against RGNNV Infection in vitro}

The aptamers could inhibit RGNNV infection (Figure 4). As shown in Figure 4A, the cells grew well for $24 \mathrm{~h}$ when cultured with aptamer (GBN34) only. When exposed to RGNNV with/without the ssDNA library, extensive CPEs were observed. However, the few CPEs that appeared in the cells incubate with mixtures of aptamer (GBN2, GBN10, or GBN34) and RGNNV. Similarly, compared with the controls, qRT-PCR and WB showed a reduction in the relative expression of viral $\mathrm{CP}$ mRNA and protein level in the cells treated with both aptamer and RGNNV. Among the three aptamers, GBN2 showed the strongest capacity to reduce CP mRNA expression, suggesting that this aptamer inhibits RGNNV infection (Figures 4B,C). The inhibition of RGNNV infection by the aptamer was dosedependent (Figures 4D,E). Aptamers showed little antiviral effects against RGNNV-infected cells at $12 \mathrm{~h}$ post supplement of aptamers (24 hp.i.) (Figures 4F,G).

\section{Antiviral Effects of Aptamers Against RGNNV Infection in vivo}

The aptamers also inhibited RGNNV infection in vivo. Ten days after injection, the groupers in the control groups, treated with PBS or aptamer, grew and were healthy, and no fish died. When injected with RGNNV only, $10 \%$ of the groupers died on day 2, and all the groupers died after 5 days post infection. The diseased groupers displayed several clinical signs, 
A
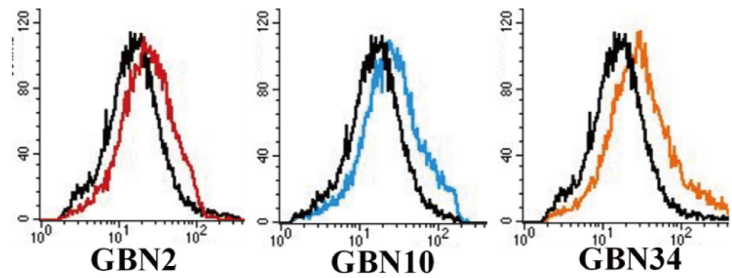

C
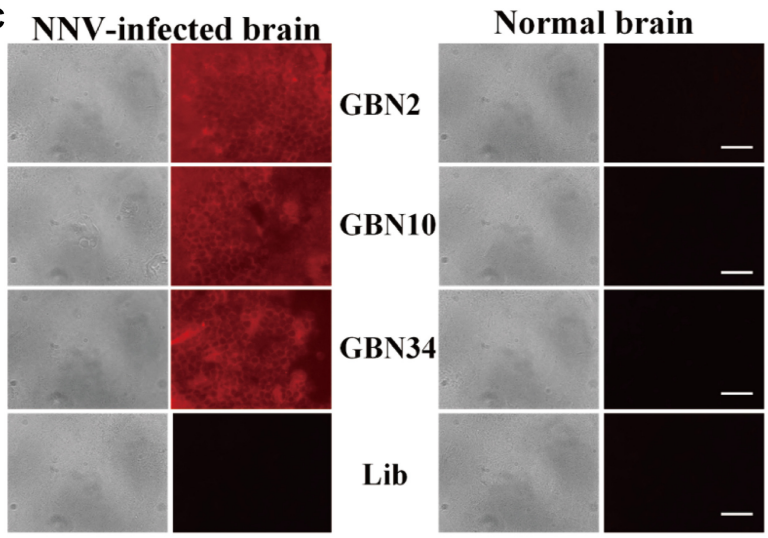

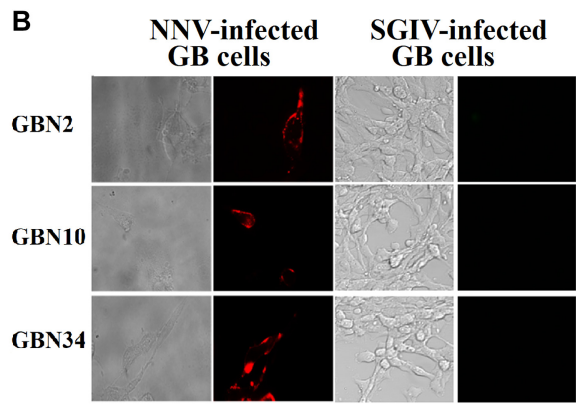

D
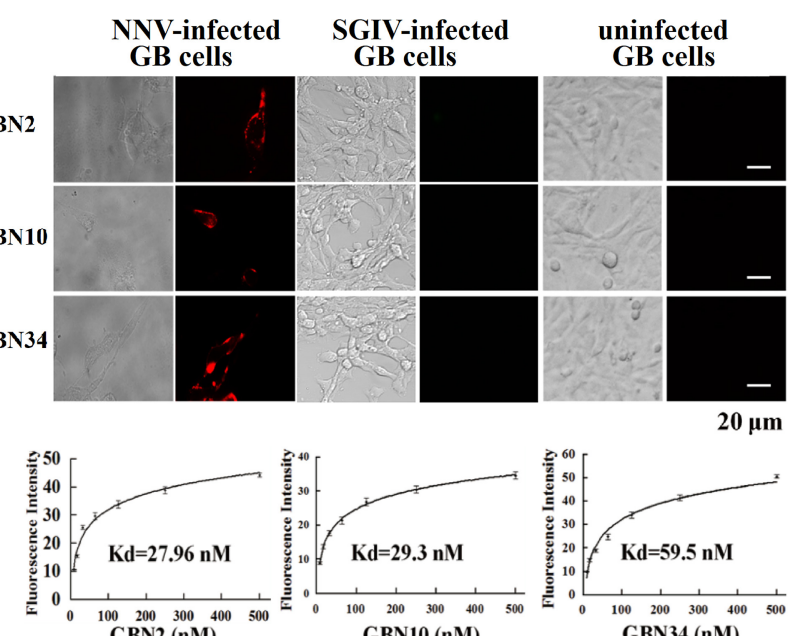

E

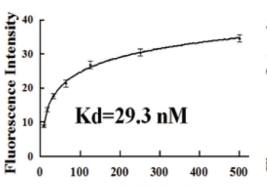

GBN10 (nM)

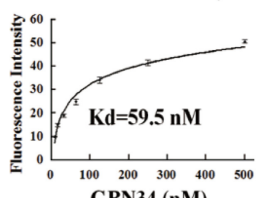

GBN34 (nM)

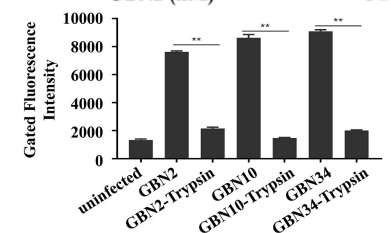

FIGURE 2 | Binding specificity and affinity of three aptamers for RGNNV-infected GB cells. (A) Increased fluorescence intensity revealed the binding ability of each FITC-labeled aptamer (red, GBN2; blue, GBN10; orange, GBN34) for RGNNV-infected GB cells. Each FITC-labeled aptamer was tested against uninfected GB cells as controls (black). (B) Specific binding of each TAMARA-labeled aptamer to RGNNV-infected GB cells, SGIV-infected GB, or uninfected GB cells. Left, bright-field microscopy; right, fluorescence microscopy. Scale bars indicate $20 \mu \mathrm{m}$. (C) Fluorescent images of the three TAMRA-labeled aptamers binding to infected brain tissues. Normal brain tissues and the TAMRA-labeled initial library were used as controls. Left, bright-field images; right, fluorescence microscopic images. Scale bars indicate $50 \mu \mathrm{m}$. (D) Affinity of each aptamer for RGNNV-infected GB cells. Binding affinities of GBN2, GBN10, and GBN34 for RGNNV-infected GB cells were 27.96, 29.3, and $59.5 \mathrm{nM}$, respectively. (E) Changes in fluorescence intensities of aptamers that bound to RGNNV-infected GB cells treated with trypsin.

including whirling and spiraling. This was also observed in the group treated simultaneously with RGNNV and the random ssDNA library. However, when the groupers were simultaneously injected with RGNNV and an aptamer, no fish died within the first 3 days. The cumulative mortality reached 80 or $40 \%$ on day 6 in the groups treated with RGNNV premixed with GBN2 or GBN34, respectively. No fish died between days 7 and 10 . These results indicated that the generated aptamers could inhibit RGNNV infection in groupers (Figure 5).

\section{Cell-Specific Internalization of Aptamer}

The specific internalization of aptamer by RGNNV-infected cells was observed with fluorescence microscopy. After incubation with the FITC-labeled aptamer GBN34 (200 nM) for $2 \mathrm{~h}$, we observed the fluorescent signal of FITC inside the RGNNV-GB cells. In contrast, no obvious fluorescent signal was detected inside the GB cells incubated with the FITC-labeled random ssDNA library or uninfected GB cells (Figure 6A).

As incubation temperature of $4^{\circ} \mathrm{C}$ could end cell activity and block the possible active endocytosis, it made aptamers only bind to the targets on the cell surface (Figure 2B). Flow cytometry results showed that fluorescence values of FAM-labeled GBN34 incubated with RGNNV-infected cells at $28^{\circ} \mathrm{C}$ were much more than at $4^{\circ} \mathrm{C}$ (Figure 6B). The results showed the specific active internalization of aptamer GBN34 into RGNNV-infected cells.

\section{Cellular Delivery of Aptamer-siRNA Conjugate to Inhibit RGNNV Infection}

On average, each aptamer-siRNA conjugate contained a streptavidin molecule, two Bio-siRNA molecules, and two Bio-aptamer molecules. A gel-shift analysis confirmed the conjugation of the aptamer and siRNA to streptavidin (Figure 7A).

The potency of siRNA alone in silencing viral CP expression was determined. siRNA at a final concentration of 100 or $200 \mathrm{nM}$ significantly reduced the relative $\mathrm{CP} \mathrm{mRNA}$ expression, at $48 \mathrm{hp}$.i. The biotin label did not significantly affect the silencing efficiency (Figures 7B,C).

Compared with the control cells incubated with RGNNV alone, the relative CP mRNA expression decreased by $36.0 \%$ at $48 \mathrm{hp}$.i. in the cells exposed to mixtures of RGNNV and aptamer $(100 \mathrm{nM})$, and by $75 \%$ in the cells exposed to mixtures of RGNNV and the aptamer-siRNA conjugates $(50 \mathrm{nM})$. These results demonstrate that the cellular delivery of the aptamer-siRNA conjugate contributed to the inhibition of RGNNV infection. The efficiency of the delivery system (reducing infection by $75 \%$ at $48 \mathrm{hp}$.i.) was only slightly inferior to that achieved with a transfection system, which reduced CP expression by $87.2 \%$ at $48 \mathrm{hp}$. i., indicating that the aptamer is potentially an excellent targeted carrier (Figure 7D). The conjugates also showed antiviral effects against RGNNV-infected cells (Figure 7E). 

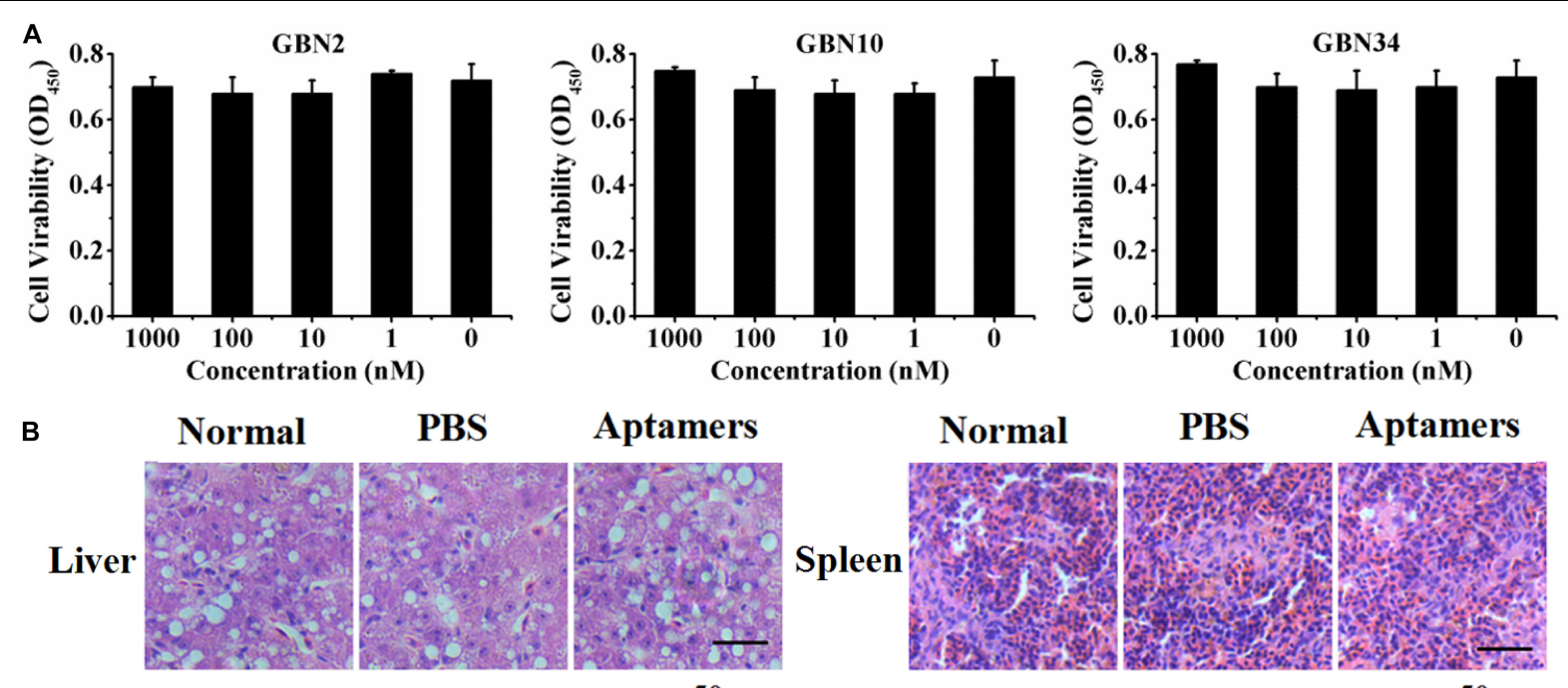

Aptamers
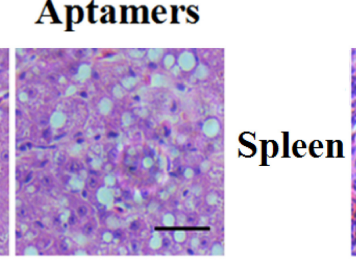

Normal

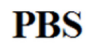

Aptamers

C
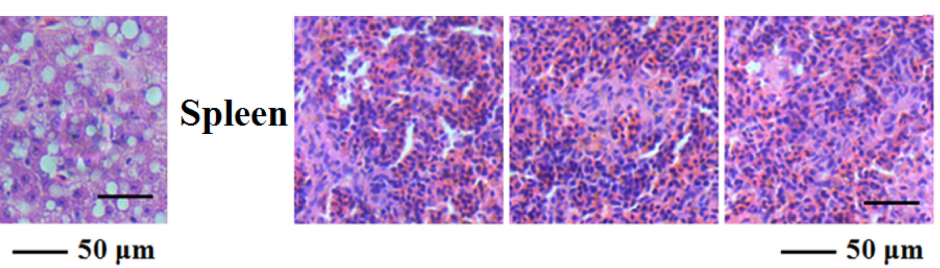

$-50 \mu \mathrm{m}$

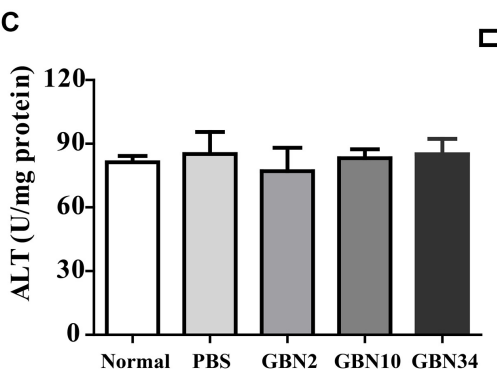

口 Normal $\square$ PBS $\square$ GBN2
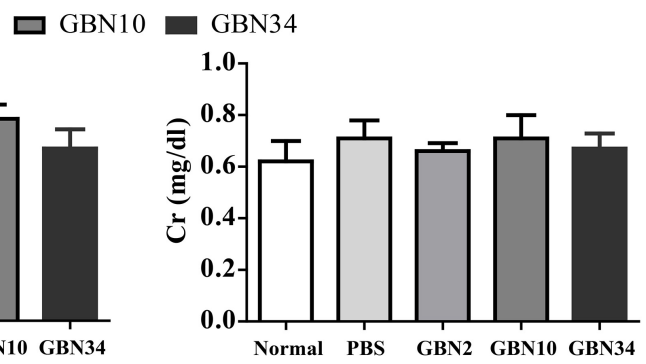

FIGURE 3 | Cytotoxicity and histological toxicity assays. (A) Cytotoxicity of each aptamer serially diluted to a concentration gradient (0, 1 , 10 , 100 , or 1000 nM) was measured with a colorimetric assay based on the cell proliferation reagent WST-1. All three aptamers showed no significant cytotoxic effects on GB cells, even at high concentrations of $1000 \mathrm{nM}$. Results of three independent experiments were averaged. (B) Histological toxicity analysis of GBN34 also showed no obvious pathological changes in the liver or spleen tissues of the tested fish. (C) Analysis of activity of ALT, AST of liver, and serum Cr. ( ${ }^{\star \star} P<0.01$; ${ }^{\star} P<0.05$ ).

\section{DISCUSSION}

Viral nervous necrosis is a serious disease causing mass mortality in larval and juvenile fish worldwide, resulting in great economic impact on the aquaculture of many fish species (Gye and Nishizawa, 2019). However, no biomarkers are available for the development of effective diagnosis or efficient drugs for the treatment against NNV (Liu et al., 2015). Therefore, the development of rapid diagnostic and therapeutic methods for VNN is urgently required. Aptamers are attractive molecular recognition ligands for use in both diagnostics and therapeutics because of their numerous advantages, including high specificity and affinity for targets, strong stability, no toxicity, and ease of synthesis (Syed and Pervaiz, 2010; Alshaer et al., 2018; Bouvier-Müller and Ducongé, 2018). Here, we applied Cell-SELEX to generate three aptamer-targeted RGNNVinfected GB cells. The aptamers displayed anti-RGNNV activities in vitro and in vivo. Furthermore, as the aptamers could be internalized into RGNNV-GB cells, they had potential utility as delivery agents. To the best of our knowledge, this is the first study to report aptamers directed against RGNNVinfected grouper cells.
Aptamers fold into distinct and stable structures, which underlie their ability to bind to and interrupt the functions of their targets. The diverse secondary and advanced structures of aptamers allow them to bind to a wide variety of targets, including small-molecule compounds, proteins, viruses, and whole cells, by hydrogen bonds, the stacking of aromatic rings, van der Waals forces, or a combination of these (Syed and Pervaiz, 2010). In the present study, all three aptamers were predicted to form stable stem-loop structures, with $\Delta G$ values of $-6.28,-19.25$, and $-18.84 \mathrm{~kJ} / \mathrm{mol}$ for GBN2, GBN10, and GBN34, respectively. They also specifically recognized RGNNV-GB cells. The diversity of aptamers' secondary structures results in complex distinct three-dimensional structures, leading to different affinities of the aptamers for their targets (Stoltenburg et al., 2007). The three aptamers showed high affinities for RGNNV-GB cells, with calculated dissociation constants $\left(K_{d}\right)$ of $27.96,29.3$, and $59.5 \mathrm{nM}$ for GBN2, GBN10, and GBN34, respectively. The affinities at the nanomolar level are competitive with those of many antibodies and are consistent with the results of previous studies (Toh et al., 2015).

As a new generation of molecular recognition elements, aptamers have been widely used to replace traditional 


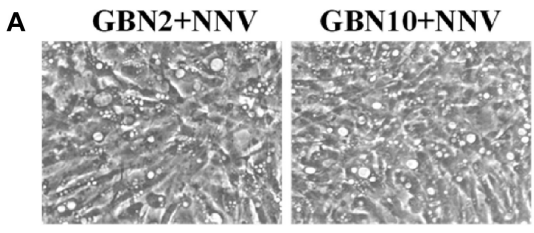

B

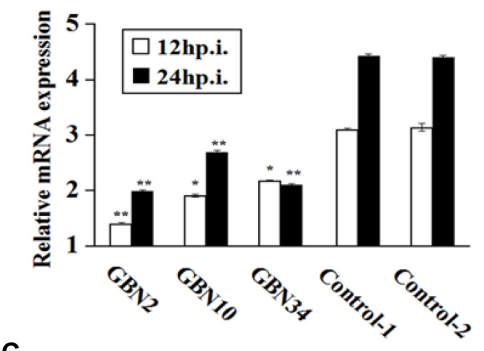

C

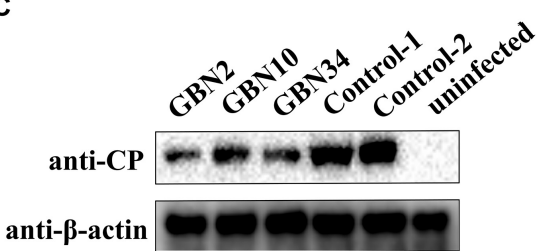

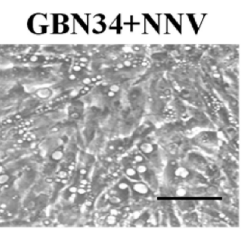

D

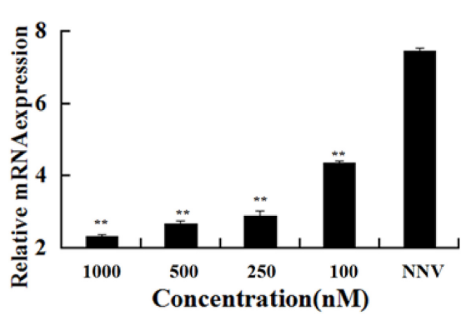

E

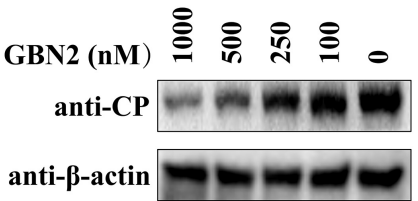

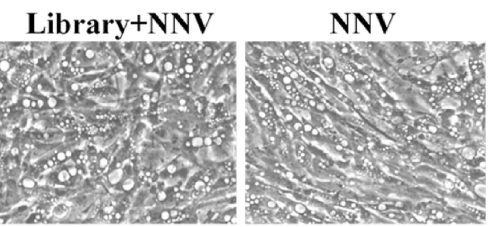

F

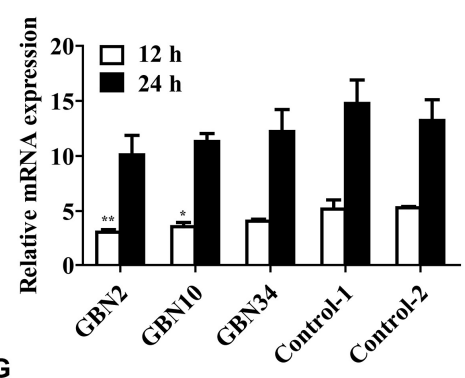

G

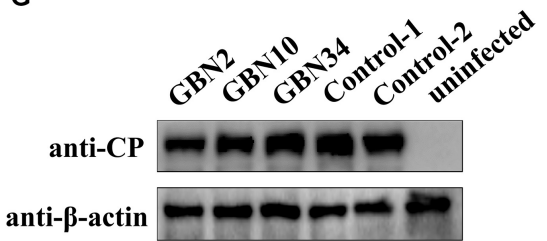

FIGURE 4 | Inhibition of RGNNV infection by selected aptamers in vitro. (A) Cell morphology and cytopathic effects (vacuolation) after infection with RGNNV, with or without added aptamer. (B,C) Relative CP mRNA expression (B) and CP level $\mathbf{( C )}$ were measured to determine the antiviral activity of the aptamer in cultured GB cells. (D,E) Aptamers inhibited RGNNV infection in a dose-dependent manner showed by relative CP mRNA expression (D) and CP level (E). (F,G) Relative CP mRNA expression (F) and CP level (G) was determined to assess the curative effect of the aptamers in cultured GB cells. $\left({ }^{\star \star} P<0.01 ;{ }^{\star} P<0.05\right)$.

molecular recognition elements, such as antibodies, in disease diagnostic systems (Wang et al., 2011; Zhou et al., 2014). Because virus-infected cells or cancer cells are often associated with deviations in certain molecular signatures compared with uninfected or normal cells, the detection and measurement of these marker molecules are key steps in developing diagnostic techniques. Li et al. (2016) developed an aptamer-based enzyme-linked aptasorbent assay to detect Singapore grouper iridovirus (SGIV) infection using an aptamer targeting SGIV-infected grouper spleen cells. In the present study, the three aptamers recognized not only RGNNV-GB cells, but also RGNNV-infected grouper brain tissue, whereas they did not bind to uninfected cells or brain tissue, demonstrating their excellent potential utility in RGNNV diagnosis.

The results concluded that the aptamers' target molecules of GBN2, GBN10, and GBN34 might be directly or indirectly related to surface proteins anchored on the RGNNV-infected GB cell membrane, as they were trypsin-sensitive. Cell membrane proteins have important effects in various physiological functions, for example, the abnormal expression of membrane proteins in cancer cells. After being infected by virus, cell membrane is modified by the insertion of viral proteins or variation of host proteins. These insertion and alterations could be important biomarkers in viral pathogenesis studies (Kim et al., 2018; Zhu and Chen, 2018; Yu et al., 2019b). However, it was always difficult to isolate such membrane proteins because of the low solubility and low abundance.

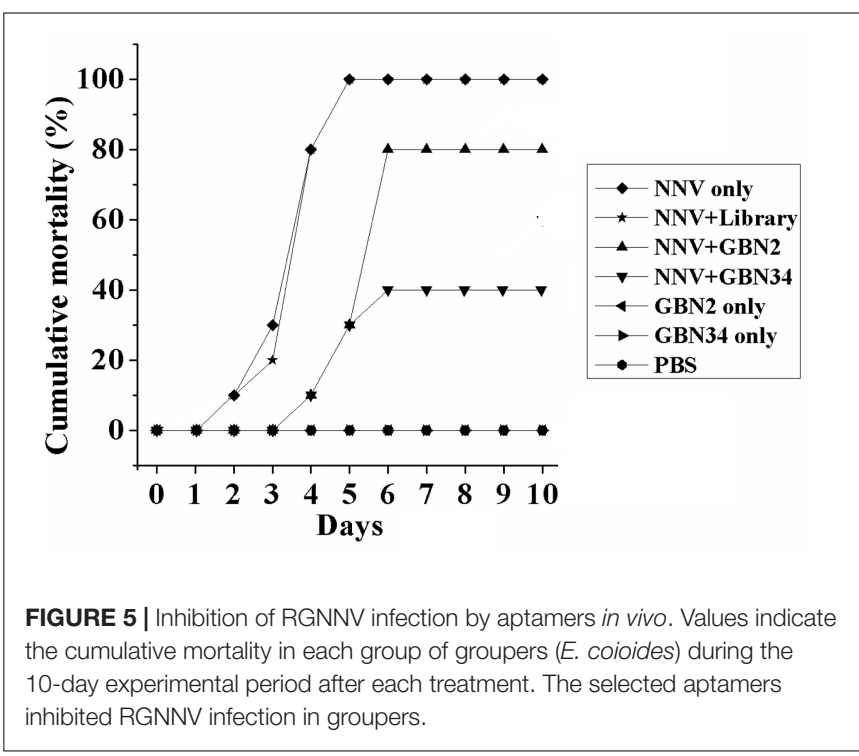

The greatest advantage of aptamers in disease diagnosis is that the complex and time-consuming process of marker identification can be circumvented. Many recent studies have demonstrated that aptamers selected with Cell-SELEX are useful tools for biomarker discovery and identification (Fang and Tan, 2010). For example, Yu et al. (2019c) identified major capsid protein (MCP) as a potential biomarker of grouper iridovirus-infected cells using aptamers. Liu et al. 


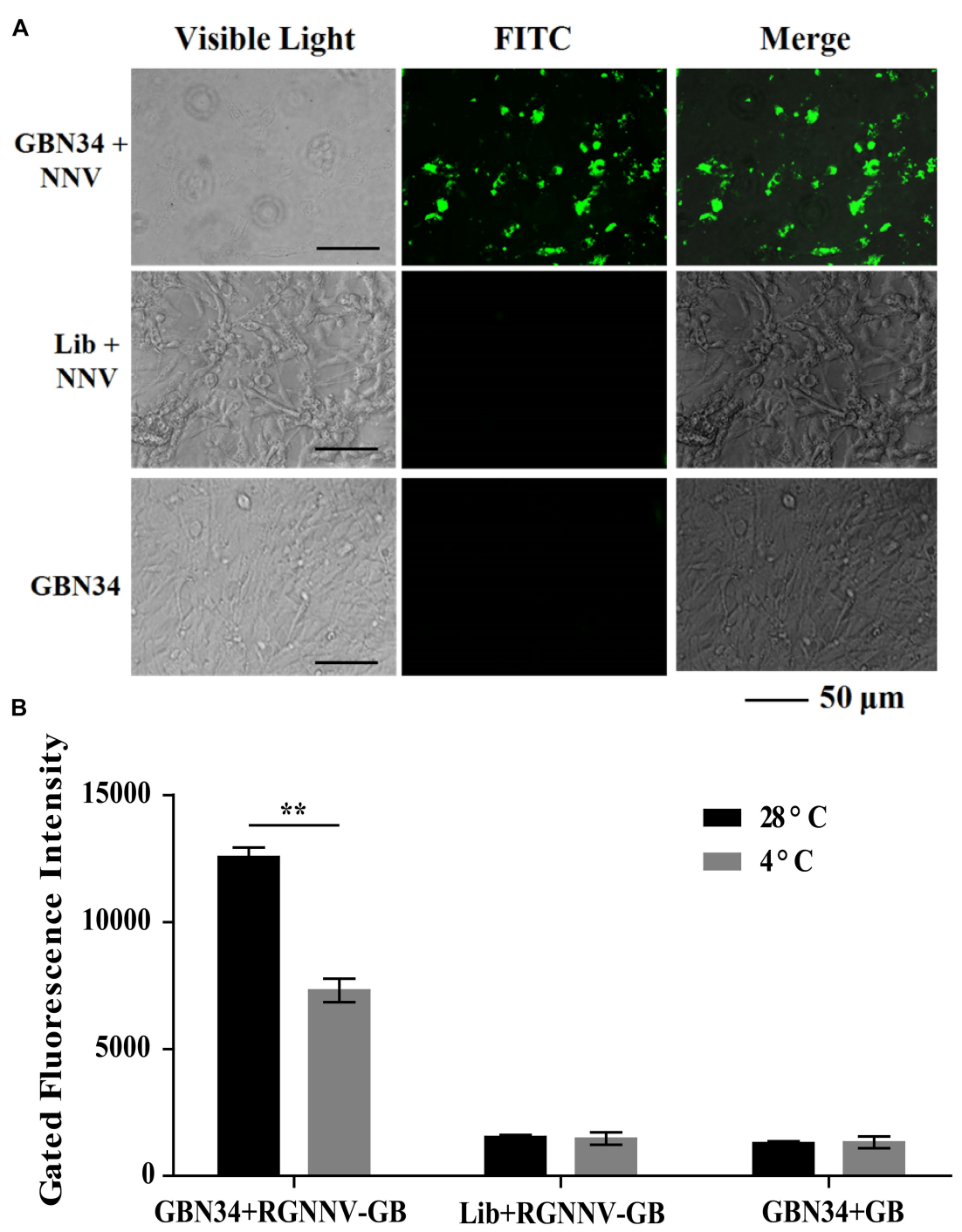

FIGURE 6 | Cell-specific internalization of aptamer GBN34. (A) Fluorescent images of FlTC-labeled GBN34 after incubation with RGNNV-infected cells for 2 h at $28^{\circ} \mathrm{C}$. Scale bars indicate $50 \mu \mathrm{m}$. (B) Internalization analysis of GBN34. Fluorescence values of FAM-labeled GBN34 incubated with RGNNV-infected cells at $28^{\circ} \mathrm{C}$ were much more than at $4^{\circ} \mathrm{C}$, with the specific active internalization of aptamer GBN34 into RGNNV-infected cells.

(2009) successfully used aptamers against liver cancer cells to develop sensitive aptamer-nanoparticle strip biosensors for cancer cells, in the absence of any explicit biomarker. Simaeys et al. (2014) identified membrane protein stressinduced phosphoprotein 1 (STIP1) as the target of applied aptamer TOV6, which was generated against ovarian clear cell adenocarcinoma TOV-21G. Aptamer S3 was selected to target NPC 5-8F cells. Using mass spectrometry, membrane protein CD109 was identified as the target of aptamer S3, and a further study identified CD109 as a biomarker of nasopharyngeal carcinoma (Jia et al., 2016). These results suggested that aptamers had a great potential in cell biomarker identification. Although a large number of studies have concentrated on the isolation and identification of RGNNV, its clinical symptoms, and epidemiology, there have been few studies of the biomarkers of RGNNV infection. To address these limits, we would develop the novel molecular probes aptamers, in the combination of two-dimensional gel electrophoresis (2D-GE) and mass spectrometry (MS), to isolate and identify the cell-specific membrane biomarkers for the specific recognition and identification of biomarkers in RGNNV-infected cell membrane in the future study. Based on their ability to distinguish RGNNVinfected and -uninfected cells, the three aptamers developed here could be used to identify the signature molecules of RGNNV infection.

Most antivirus medicines display antiviral effects by disturbing the process of virus infection (Liu et al., 2019). Wang et al. (2016) identified (-)-epigallocatechin-3-gallate as a potential agent for blocking infection of grass carp reovirus. Liang et al. (2013) reported aptamers that targeted rabies virus (RABV)-infected cells, displaying anti-RABV activity. In our 


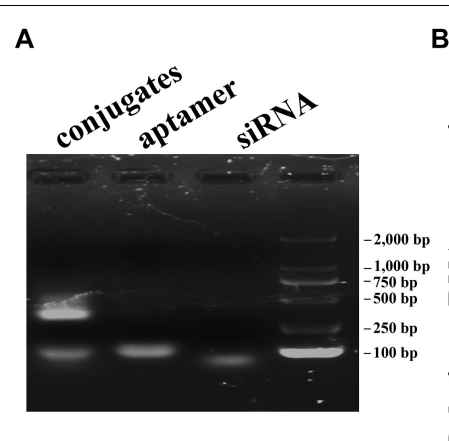

D

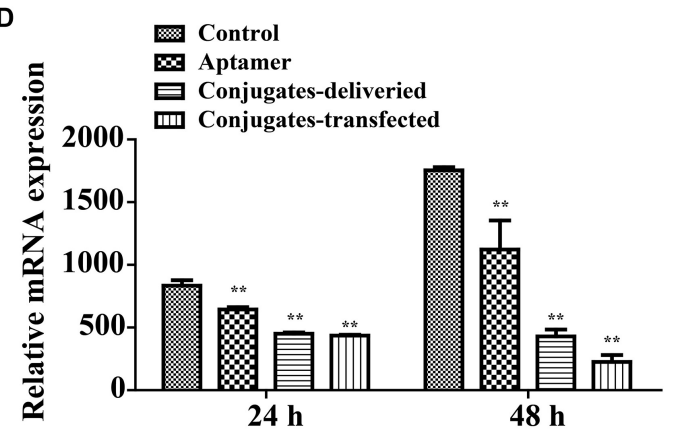

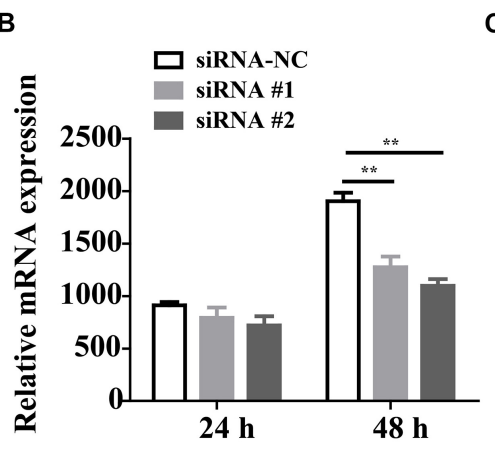
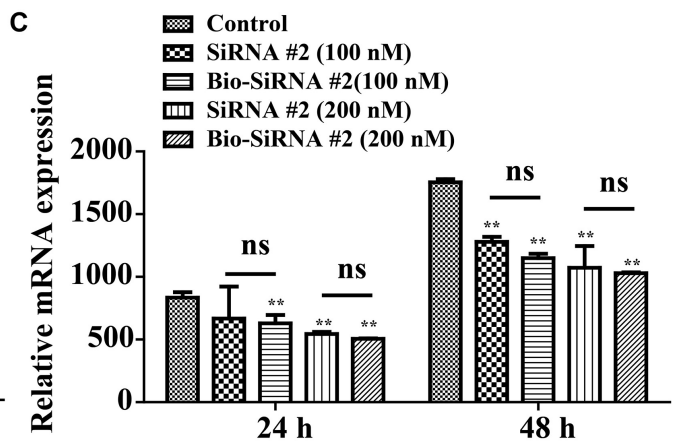

E

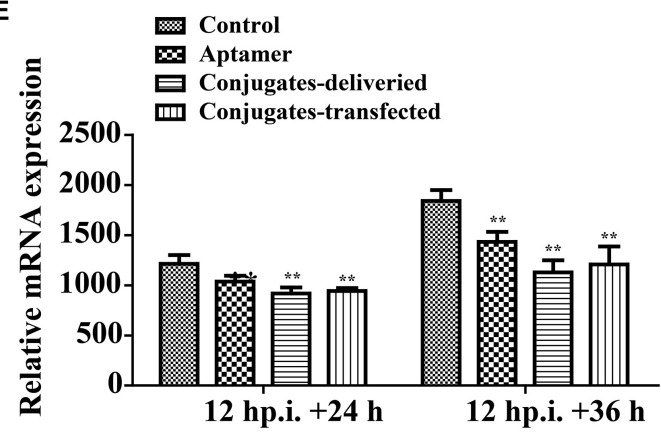

FIGURE 7 | Aptamer conjugate for the delivery of functional siRNA. (A) Gel-shift analysis confirmed the conjugation of the Bio-aptamer and Bio-siRNA to streptavidin. (B) Gene silencing efficiency of siRNA for CP. (C) The biotin label did not significantly affect the silencing efficiency. (D) Inhibition of RGNNV infection by aptamer-siRNA conjugate. Compared with the control cells incubated with RGNNV alone, the relative CP mRNA expression decreased by $36.0 \%$ at 48 hp.i. in the cells exposed to mixtures of RGNNV and aptamer (100 nM) and by $75 \%$ in the cells exposed to mixtures of RGNNV and the aptamer-siRNA conjugates (50 nM). The efficiency of the delivery system (75\% reduction in CP mRNA expression at $48 \mathrm{hp}$.i.) was slightly inferior to that of a transfection system, which reduced CP mRNA expression by $87.2 \%$ at 48 hp.i. (E) The conjugates showed relatively less antiviral effect against RGNNV-infected cells (24 hp.i.). ( ${ }^{\star \star} P<0.01$; $\left.{ }^{\star} P<0.05\right)$.

study, the three aptamers also inhibited RGNNV infection. An in vitro experiment indicated that the inhibition of RGNNV infection by the aptamers was dose-dependent. Among the three aptamers, GBN2 showed the greatest ability to reduce the expression of $\mathrm{CP}$ mRNA in GB cells. An in vivo experiment showed that GBN2 and GBN34 reduced the cumulative mortality of infected fish by 20 and $60 \%$, respectively. The little antiviral effects of aptamers against RGNNV-infected cells at 24 hp.i. proved that aptamers could display the antiviral effects against RGNNV during the viral infection stage of binding and entering to host cells, but not virus replication in host cells. The antiviral mechanism of aptamers could be that aptamers specifically bind to virus-infected cells with high affinity and interact with their targets, usually biomarkers of viral infection. Interaction of aptamer and its target results in the conformation change of their targets and blocking their functions (Fang and Tan, 2010; Yu et al., 2019c). Therefore, aptamers act as potential antiviral agents. Cytotoxicity and histological toxicity analyses also showed that our aptamers are non-toxic, consistent with previous reports (Syed and Pervaiz, 2010; Ye et al., 2012). These results suggest that GBN2 and GBN34 can be used in RGNNV-targeting therapies. More systemic studies should be done to explore the possible antiviral mechanisms of aptamers against RGNNV in the future.

For clinical applications, drugs should only enter diseased cells, thereby limiting the adverse effects of their non-specific activities in normal cells (Sawyers, 2004). Aptamers that bind cells and are subsequently internalized are highly desirable tools that specifically deliver molecules into cells (Chu et al., 2006), and aptamers have been successfully used to deliver siRNAs, toxins, anticancer drugs, and so on (Zhou et al., 2017). Farokhzad et al. (2004) demonstrated that aptamers directed against prostate-specific membrane antigen (PSMA) were internalized. Based on this result, Bagalkot et al. (2007) established a quantum dot-aptamer-doxorubicin conjugate that could be used as a targeted cancer therapy. Chu et al. (2006) used streptavidin to conjugate the biotin-labeled anti-PSMA aptamer to siRNA, and used this system to inhibit the target gene in cultured cells. Fluorescence microscopy and flow cytometry demonstrated that the aptamer GBN34 was efficiently and specifically internalized by RGNNV-GB cells at a constant rate for $4 \mathrm{~h}$. Considering its non-toxicity, GBN34 has great potential utility in targeted intracellular delivery. Therefore, we assembled an aptamer-siRNA conjugate by mixing biotinlabeled siRNA and the aptamer, conjugated with streptavidin, in a molar ratio of 2:2:1 for $15 \mathrm{~min}$. The conjugation to streptavidin was confirmed with a gel-shift analysis. An antiviral study in GB cells showed that the cellular delivery of the aptamer-siRNA conjugate contributed to the inhibition of RGNNV infection. The efficiency of the delivery system was similar to that of a transfection system (75\% reduction in infection at 48 hp.i.). However, with the delivery system, no 
additional treatment was required, such as transfection with Lipofectamine 2000. These results suggest that GBN34 is an efficient delivery agent. The use of the aptamer-siRNA conjugate may provide a convenient and efficient way to inhibit RGNNV.

\section{CONCLUSION}

In this study, we generated three aptamers targeting RGNNVinfected GB cells by Cell-SELEX method. These aptamers specifically recognized RGNNV infection in vitro and in vivo with high affinity in the nanomolar range. Antiviral analysis showed that the aptamers could inhibit RGNNV infection both in vitro and in vivo. The selected aptamers were also specifically internalized by RGNNV-GB cells, showing their potential utility as delivery agents. Our findings provide new insight into the applicability of aptamers developed with Cell-SELEX to RGNNV diagnosis and inhibition.

\section{DATA AVAILABILITY STATEMENT}

The raw data supporting the conclusion of this article will be made available by the authors, without undue reservation, to any qualified researcher.

\section{REFERENCES}

Alshaer, W., Hillaireau, H., and Fattal, E. (2018). Aptamer-guided nanomedicines for anticancer drug delivery. Adv. Drug Deliv. Rev. 134, 122-137. doi: 10.1016/ j.addr.2018.09.011

Bagalkot, V., Zhang, L., Levy-Nissenbaum, E., Jon, S., Kantoff, P. W., Langer, R., et al. (2007). Quantum dot - Aptamer conjugates for synchronous cancer imaging, therapy, and sensing of drug delivery based on Bi-fluorescence resonance energy transfer. Nano Lett. 7, 3065-3070. doi: 10.1021/nl071546n

Bouvier-Müller, A., and Ducongé, F. (2018). Application of aptamers for in vivo molecular imaging and theranostics. Adv. Drug Deliv. Rev. 134, 94-106. doi: 10.1016/j.addr.2018.08.004

Chapman, J. A., and Beckey, C. (2006). Pegaptanib: a novel approach to ocular neovascularization. Ann. Pharmacother. 40, 1322-1326. doi: 10.1345/aph. $\lg 604$

Chenna, R., Sugawara, H., Koike, T., Lopez, R., Gibson, T. J., Higgins, D. G., et al. (2003). Multiple sequence alignment with the Clustal series of programs. Nucleic Acids Res. 31, 3497-3500. doi: 10.1093/nar/gkg500

Chu, T. C., Twu, K. Y., Ellington, A. D., and Levy, M. (2006). Aptamer mediated siRNA delivery. Nucleic Acids Res. 34:e73. doi: 10.1093/nar/gkl388

Doan, Q., Vandeputte, M., Chatain, B., Morin, T., and Allal, F. (2017). Viral encephalopathy and retinopathy in aquaculture: a review. J. Fish Dis. 40, 717-742. doi: 10.1111/jfd.12541

Dyke, C. K., Steinhubl, S. R., Kleiman, N. S., Cannon, R. O., Aberle, L. G., Lin, M., et al. (2006). First-in-human experience of an antidote-controlled anticoagulant using RNA aptamer technology - A phase la pharmacodynamic evaluation of a drug-antidote pair for the controlled regulation of factor IXa activity. Circulation 114, 2490-2497. doi: 10.1161/circulationaha.106.668434

Fang, X. H., and Tan, W. H. (2010). Aptamers generated from Cell-SELEX for molecular medicine: a chemical biology approach. Acc. Chem. Res. 43, 48-57. doi: 10.1021/ar900101s

Farokhzad, O. C., Jon, S., Khademhosseini, A., Tran, T. N., Lavan, D. A., and Langer, R. (2004). Nanoparticle-aptamer bioconjugates: a new approach for

\section{ETHICS STATEMENT}

The animal study was reviewed and approved by the Ethical Committee of College of Marine Sciences, South China Agricultural University.

\section{AUTHOR CONTRIBUTIONS}

QQ and PL conceived and directed this study, and revised the manuscript. LZ and PL performed the experiments, analyzed the data, and wrote the manuscript. SWW, QY, SW, and ML performed the experiments and analyzed the data. JW, YH, and $\mathrm{XH}$ analyzed the data and revised the manuscript. All authors approved the manuscript to be published.

\section{FUNDING}

This work was supported by grants from the Guangdong MEPP Fund (GDME-2018C002), the National Natural Science Foundation of China (31930115), the China Postdoctoral Science Foundation (2018M640853), the Key Research and Development Programs of Guangxi (2018AB52003), the Natural Science Foundation of Guangxi (2019GXNSFAA245054, AD19245022, and 2019JJB130070), and the Basic Research Fund of Guangxi Academy of Sciences (2019YJJ1005, 2018YJJ903, and 2018YJJ902).

targeting prostate cancer cells. Cancer Res. 64, 7668-7672. doi: 10.1158/00085472.can-04-2550

Fattal, E., Hillaireau, H., and Ismail, S. (2018). Aptamers in therapeutics and drug delivery. Adv. Drug Deliv. Rev. 134, 1-2. doi: 10.1016/j.addr.2018.11.001

Gye, H. J., and Nishizawa, T. (2019). Altered conformational structures of nervous necrosis virus surface protrusions and free coat proteins after incubation at moderate-low temperatures. Sci. Rep. 9, 1-10. doi: 10.1038/s41598-019-450942

Huang, X., Huang, Y., Ouyang, Z., and Qin, Q. (2011). Establishment of a cell line from the brain of grouper (Epinephelus akaara) for cytotoxicity testing and virus pathogenesis. Aquaculture 311, 65-73. doi: 10.1016/j.aquaculture.2010.11.037

Huang, Y., Huang, X., Cai, J., OuYang, Z., Wei, S., Wei, J., et al. (2015). Identification of orange-spotted grouper (Epinephelus coioides) interferon regulatory factor 3 involved in antiviral immune response against fish RNA virus. Fish Shellfish Immunol. 42, 345-352. doi: 10.1016/j.fsi.2014.11.025

Jia, W. T., Ren, C. P., Wang, L., Zhu, B., Jia, W., Gao, M. H., et al. (2016). CD109 is identified as a potential nasopharyngeal carcinoma biomarker using aptamer selected by cell-SELEX. Oncotarget 7, 55328-55342. doi: 10.18632/oncotarget. 10530

Kim, D. T. H., Bao, D. T., Park, H., Ngoc, N. M., and Yeo, S. J. (2018). Development of a novel peptide aptamer-based immunoassay to detect Zika virus in serum and urine. Theranostics 8, 3629-3642. doi: 10.7150/thno. 25955

Kovacevic, K. D., Gilbert, J. C., and Jilma, B. (2018). Pharmacokinetics, pharmacodynamics and safety of aptamers. Adv. Drug Deliv. Rev. 134, 36-50. doi: 10.1016/j.addr.2018.10.008

Lee, S., Kim, Y. S., Jo, M. J., Jin, M., Lee, D. K., and Kim, S. (2007). Chip-based detection of hepatitis $\mathrm{C}$ virus using RNA aptamers that specifically bind to HCV core antigen. Biochem. Biophys. Res. Commun. 358, 47-52. doi: 10.1016/j.bbrc. 2007.04.057

Li, P., Wei, S., Zhou, L., Yang, M., Yu, Y., Wei, J., et al. (2015a). Selection and characterization of novel DNA aptamers specifically recognized by Singapore grouper iridovirus-infected fish cells. J. Gen. Virol. 96, 3348-3359. doi: 10.1099/ jgv.0.000270 
Li, P., Yan, Y., Wei, S., Wei, J., Gao, R., Huang, X., et al. (2014). Isolation and characterization of a new class of DNA aptamers specific binding to Singapore grouper iridovirus (SGIV) with antiviral activities. Virus Res. 188, 146-154. doi: 10.1016/j.virusres.2014.04.010

Li, P., Zhou, L., Wei, J., Yu, Y., Yang, M., Wei, S., et al. (2016). Development and characterization of aptamer-based enzyme-linked apta-sorbent assay for the detection of Singapore grouper iridovirus infection. J. Appl. Microbiol. 121, 634-643. doi: 10.1111/jam.13161

Li, P., Zhou, L., Yu, Y., Yang, M., Ni, S., Wei, S., et al. (2015b). Characterization of DNA aptamers generated against the soft-shelled turtle iridovirus with antiviral effects. BMC Vet. Res. 11:245. doi: 10.1186/s12917-015-0559-6

Liang, H.-R., Liu, Q., Zheng, X.-X., Gai, W.-W., Xue, X.-H., Hu, G.-Q., et al. (2013). Aptamers targeting rabies virus-infected cells inhibit viral replication both in vitro and in vivo. Virus Res. 173, 398-403. doi: 10.1016/j.virusres.2012. 12.017

Liu, G. D., Mao, X., Phillips, J. A., Xu, H., Tan, W. H., and Zeng, L. W. (2009). Aptamer-nanoparticle strip biosensor for sensitive detection of cancer cells. Anal. Chem. 81, 10013-10018. doi: 10.1021/ac901889s

Liu, H., Teng, Y., Zheng, X. X., Wu, Y. R., Xie, X. Y., He, J. Q., et al. (2012). Complete sequence of a viral nervous necrosis virus (NNV) isolated from red-spotted grouper (Epinephelus akaara) in China. Arch. Virol. 157, 777-782. doi: 10.1007/s00705-011-1187-5

Liu, M., Xiao, H., Zhang, Q., Wu, S., Putra, D., Xiong, X., et al. (2019). Antiviral abilities of Curcuma kwangsiensis ingredients against grouper iridoviral infection in vitro and in vivo. Aquac. Res. 51, 351-361. doi: 10.1111/are. 14382

Liu, X. D., Huang, J. N., Weng, S. P., Hu, X. Q., Chen, W. J., Qin, Z. D., et al. (2015). Infections of nervous necrosis virus in wild and cage-reared marine fish from South China Sea with unexpected wide host ranges. J. Fish Dis. 38, 533-540. doi: $10.1111 /$ jfd. 12265

Munday, B. L., Kwang, J., and Moody, N. (2002). Betanodavirus infections of teleost fish: a review. J. Fish Dis. 25, 127-142. doi: 10.1046/j.1365-2761.2002.00350.x

Nishizawa, T., Furuhashi, M., Nagai, T., Nakai, T., and Muroga, K. (1997). Genomic classification of fish nodaviruses by molecular phylogenetic analysis of the coat protein gene. Appl. Environ. Microbiol. 63, 1633-1636. doi: 10.1128/aem.63.4. 1633-1636.1997

Parekh, P., Tang, Z., Turner, P. C., Moyer, R. W., and Tan, W. (2010). Aptamers recognizing glycosylated hemagglutinin expressed on the surface of vaccinia virus-infected cells. Anal. Chem. 82, 8642-8649. doi: 10.1021/ac101801j

Paul, A., Avci-Adali, M., Ziemer, G., and Wendel, H. P. (2009). Streptavidin-coated magnetic beads for DNA strand separation implicate a multitude of problems during cell-SELEX. Oligonucleotides 19, 243-254. doi: 10.1089/oli.2009.0194

Reed, L. J., and Muench, H. (1938). A simple method of estimating fifty per cent endpoints. Am. J. Epidemiol. 27, 493-497. doi: 10.1093/oxfordjournals.aje. a118408

Sawyers, C. (2004). Targeted cancer therapy. Nature 432, 294-297.

Shangguan, D., Li, Y., Tang, Z. W., Cao, Z. H. C., Chen, H. W., Mallikaratchy, P., et al. (2006). Aptamers evolved from live cells as effective molecular probes for cancer study. Proc. Natl. Acad. Sci. U.S.A. 103, 11838-11843. doi: 10.1073/pnas. 0602615103

Simaeys, D. V., Turek, D., Champanhac, C., Vaizer, J., Sefah, K., Zhen, J., et al. (2014). Identification of cell membrane protein stress-induced phosphoprotein 1 as a potential ovarian cancer biomarker using aptamers selected by cell systematic evolution of ligands by exponential enrichment. Anal. Chem. 86, 4521-4527. doi: 10.1021/ac500466x

Souto, S., Vázquez-Salgado, L., Olveira, J. G., and Bandín, I. (2019). Amino acidic substitutions in the polymerase $\mathrm{N}$-terminal region of a reassortant betanodavirus strain causing poor adaptation to temperature increase. Vet. Res. 50:50. doi: 10.1186/s13567-019-0669-4

Stoltenburg, R., Reinemann, C., and Strehlitz, B. (2007). SELEX-a (r)evolutionary method to generate high-affinity nucleic acid ligands. Biomol. Eng. 24, 381-403. doi: 10.1016/j.bioeng.2007.06.001

Syed, M. A., and Pervaiz, S. (2010). Advances in aptamers. Oligonucleotides 20, 215-224. doi: 10.1089/oli.2010.0234
Tan, W. H., Donovan, M. J., and Jiang, J. H. (2013). Aptamers from cell-based selection for bioanalytical applications. Chem. Rev. 113, 2842-2862. doi: 10. 1021/cr300468w

Toh, S. Y., Citartan, M., Gopinath, S. C. B., and Tang, T. H. (2015). Aptamers as a replacement for antibodies in enzyme-linked immunosorbent assay. Biosens. Bioelectr. 64, 392-403. doi: 10.1016/j.bios.2014.09.026

Wang, H., Liu, W., Yu, F., and Lu, L. (2016). Identification of (-)-epigallocatechin3-gallate as a potential agent for blocking infection by grass carp reovirus. Arch. Virol. 161, 1053-1059. doi: 10.1007/s00705-016-2751-9

Wang, R. E., Zhang, Y., Cai, J., Cai, W., and Gao, T. (2011). Aptamer-based fluorescent biosensors. Curr. Med. Chem 18, 4175-4184. doi: 10.2174/ 092986711797189637

Xiao, Z., Shangguan, D., Cao, Z., Fang, X., and Tan, W. (2008). Cell-specific internalization study of an aptamer from whole cell selection. Chem. A Eur. J. 14, 1769-1775. doi: 10.1002/chem.200701330

Xu, H. D., Feng, J., Guo, Z. X., Ou, Y. J., and Wang, J. Y. (2010). Detection of red-spotted grouper nervous necrosis virus by loop-mediated isothermal amplification. J. Virol. Methods 163, 123-128. doi: 10.1016/j.jviromet.2009.09. 009

Yang, D., Meng, X., Yu, Q., Xu, L., Long, Y., Liu, B., et al. (2013). Inhibition of hepatitis $\mathrm{C}$ virus infection by DNA aptamer against envelope protein. Antimicrob. Agents Chemother. 57, 4937-4944. doi: 10.1128/AAC.00897-13

Ye, M., Hu, J., Peng, M., Liu, J., Liu, J., Liu, H., et al. (2012). Generating aptamers by cell-SELEX for applications in molecular medicine. Int. J. Mol. Sci. 13, 3341-3353. doi: 10.3390/ijms13033341

Yu, Q., Liu, M., Su, H., Xiao, H., Wu, S., Qin, X., et al. (2019a). Selection and characterization of ssDNA aptamers specifically recognizing pathogenic Vibrio alginolyticus. J. Fish Dis. 42, 851-858. doi: 10.1111/jfd.12985

Yu, Q., Liu, M., Wei, S., Wu, S., Xiao, H., Qin, X., et al. (2019b). Characterization of ssDNA aptamers specifically directed against Trachinotus ovatus NNV (GTONNV)-infected cells with antiviral activities. J. Gen. Virol. 100, 380-391. doi: 10.1099/jgv.0.001226

Yu, Q., Liu, M., Wei, S., Xiao, H., Wu, S., Ke, K., et al. (2019c). Identification of major capsid protein as a potential biomarker of grouper iridovirus-infected cells using aptamers selected by SELEX. Front. Microbiol. 10:2684. doi: 10.3389/ fmicb.2019.02684

Zhou, J., and Rossi, J. J. (2012). Therapeutic potential of aptamer-siRNA conjugates for treatment of HIV-1. Biodrugs 26, 393-400. doi: 10.2165/ 11635350-000000000-00000

Zhou, L., Li, P., Ni, S., Yu, Y., Yang, M., Wei, S., et al. (2017). Rapid and sensitive detection of redspotted grouper nervous necrosis virus (RGNNV) infection by aptamer-coat protein-aptamer sandwich enzyme-linked apta-sorbent assay (ELASA). J. Fish. Dis. 40, 1831-1838. doi: 10.1111/jfd.12656

Zhou, L., Li, P., Yang, M., Yu, Y., Huang, Y., Wei, J., et al. (2016). Generation and characterization of novel DNA aptamers against coat protein of grouper nervous necrosis virus (GNNV) with antiviral activities and delivery potential in grouper cells. Antiviral Res. 129, 104-114. doi: 10.1016/j.antiviral.2016.02. 009

Zhou, W., Huang, P. J., Ding, J., and Liu, J. (2014). Aptamer-based biosensors for biomedical diagnostics. Analyst 139, 2627-2640. doi: 10.1039/c4an00132j

Zhu, G., and Chen, X. (2018). Aptamer-based targeted therapy. Adv. Drug Deliv. Rev. 134, 65-78. doi: 10.1016/j.addr.2018.08.005

Conflict of Interest: The authors declare that the research was conducted in the absence of any commercial or financial relationships that could be construed as a potential conflict of interest.

Copyright (C) 2020 Zhou, Wang, Yu, Wei, Liu, Wei, Huang, Huang, Li and Qin. This is an open-access article distributed under the terms of the Creative Commons Attribution License (CC BY). The use, distribution or reproduction in other forums is permitted, provided the original author(s) and the copyright owner(s) are credited and that the original publication in this journal is cited, in accordance with accepted academic practice. No use, distribution or reproduction is permitted which does not comply with these terms. 